\title{
PERFIL ALIMENTAR E POSSE DA TERRA NA ÁREAL RURAL DO ESTADO DE PERNAMBUCO, NORDESTES DO BRASIL *
}

Sylvia de Azevedo Mello Romani ${ }^{* *}$

Hugo Amigo ***

ROMANI, S. de A.M. \& AMIGO, H. Perfil alimentar e posse da terra na área rural do Estado de Pernambuco, Nordeste do Brasil. Rev.Saúde públ., S.Paulo, 20:369-76. 1986.

RESUMO: Foi realizado estudo na área rural do Nordeste brasileiro com uma amostra de 689 famiJias estratificadas segundo o acesso e a quantidade de terra possuída, em quatro categorias: famílias sem terra (ST), pequenos proprietários (PP) que possuíam até 10 hectares de terra, médios proprie tários (MP) de 10 a 50 hectares e grandes proprietários (GP) com mais de 50 hectares de terra. A média de ingesta energética dos ST foi de 1.605 calorias, observando-se que à medida que aumentava a quantidade de terra possuída, maior era a média de ingestão calórica, chegando a atingir mais de 3.000 calorias entre os GP que corresponde a média dos valores encontrados nos países desenvolvidos. Em termos médlios o déficit protéico não foi encontrado em nenhum dos grupos estudados. O valor calórico total (V( $\Gamma$ ) da dieta, para os quatro grupos, está representado, em média, por $13 \%$ de protídeos, $11 \%$ de lipídeos t $76 \%$ de glicídeos, observando-se tendência crescente à medida que aumenta a posse da terra com relação aos protídeos e lipídeos, e, decrescente, com relação aos glicídeos. O grupo de alimentos que mais contribuiu para o VCT foi o de "grãos e raízes", embora apresente tendência decrescente com o aumento do tamanho da propriedade. Comportamento inverso foi observado para o grupo dos "produtos animais". Não foram encontradas diferenças em relação a outros grupos de alimentos: verduras, frutas, açúcares e gorduras. cional.

UNTERMOS: Inquéritos nutricionais. Consumo de alimentos. Propriedade (da terra). Estado nutri-

\section{INTRODUÇÃO}

A situação alimentar e nutricional da população brasileira tem merecido especial atenção desde a década de 1930, através dos estudos de Castro5.

$\mathrm{Na}$ década de 60 foi realizado pela Fundação Getúlio Vargas 8 o primeiro estudo sistemático a nivel nacional, analisando o consumo alimentar de 9.125 famílias de áreas rurais e urbanas, a partir dos gastos familiares com alimentos e quantidades consumidas no último mês antes da entrevista. Ainda, nesse período, o Interdepartmental Committee For National Development (ICNND)20, com a colaboração de várias instituições brasileiras, realizou um inquérito alimentar e nutricional em 16 cidades da região nordestina. Os dados de consumo foram obtidos através do método recordatório das últimas vinte e quatro horas.

Em 1974, o Instituto Brasileiro de Geografia e Estatística (IBGE) realizou o chamado Estudo Nacional de Despesas Familiares (ENDEF) 9 , o mais completo estudo de consumo familiar realizado a nivel nacional, no Brasil. O trabalho de campo teve a duração de um ano e os dados de consumo foram obtidos através da pesagem direta dos ali- mentos durante 7 dias em 55.000 familias representativas das diferentes regiōes geográficas do país. Esse estudo contou com o apoio técnico da Organização das Nações Unidas para Agricultura e Alimentação (FAO) e é considerado como a mais rica fonte de dados sobre situação alimentar do país.

Todos esses estudos a nível nacional têm proporcionado elementos suficientes de comparabilidade $e$ permitido uma importante experiência no manejo dessas informações.

A esses estudos aliam-se pesquisas de âmbito mais restrito, as quais, apesar de não proporcionarem conhecimentos suficientes para definir o problema a nivel nacional, nem permitirem o estabelecimento de um quadro comparativo ao longo do tempo. retratam a situação alimentar de grupos populacionais localizados $3,4,6,17,19$.

Por outro lado, o estudo do consumo alimentar de uma população tem gerado série de informaçōes que, de certa forma, refletem a organização social, uma vez que a alimentação constitui necessidade prioritária em qualquer sociedade.

\footnotetext{
* Pesquisa financiada pelo "Grant Out OF DAP 739 - 0820" da Fundação FORD.

* Do Departamento de Nutrição do Centro de Ciências da Saúde da Universidade Federal de Pernambuco - Campus Universitário, s/n? - 50000 - Recife, PE - Brasil.

*** Consultor cm Nutrição da FAO junto à Secretaria de Agricultura e Abastecimento - Av. Miguel Estéfano, 3900 - 04310 - São Paulo, SP - Brasil.
} 
Em muitas regiōes do terceiro mundo, uma delas, o Nordeste brasileiro, a estrutura agrária está caracterizada pela grande concentração da terra em mãos de alguns poucos proprietários, enquanto a maioria não tem acesso à terra, configurando, cada vez mais, grandes grupos populacionais de assalariados rurais que vivem em precárias condições de vida. Existem, também, grupos de pequenos proprietários que representam os chamados minifúndios 2,18 , alijados do uso de insumos modemos, de créditos e de apoio na comercialização de seus produtos.

Neste trabalho postula-se que a estrutura da posse da terra - entendida como uma conseqüência direta do modelo de desenvolvimento adotado - determina as condições de alimentação das populações e que o aumento progressivo da concentração da terra, nas áreas rurais, conduz a uma situação alimentar cada vez mais deteriorada.

No presente estudo considerou-se importante pesquisar a adequação dos diversos nutrientes, a quantidade de alimentos consumidos e as características da dieta, analisados segundo diferentes categorias de posse da terra.

\section{METODOLOGIA}

O trabalho se desenvolveu na área rural de quatro municípios do Agreste Pernambucano, no período de abril a novembro de 1980 .

O Agreste, que abrange parte de quatro Estados do Nordeste, é uma área muito subdividida, com predomínio das pequenas propriedades, sendo que a população se dedica, basicamente, às atividades agrícolas de subsistência.

A amostra foi constituída de 689 famílias, estratificadas em quatro categorias, em função do acesso e do tamanho da propriedade: familias sem terra (ST), familias de pequenos proprietários que possuíam de 0 a 10 hectares (PP), de médios proprietários, com 10 a 50 hectares de terra (MP) e de grandes proprietários, com mais de 50 hectares (GP).

As unidades amostrais dos grandes proprietários (GP) foram selecionadas aleatoriamente a partir das informações dos arquivos do Instituto Nacional de Colonização e Reforma Agrária (INCRA). A seleção das famílias pertencentes às demais categorias foi, também, aleatória, e efetuada dentre aquelas vizinhas às grandes propriedades.

Foram determinados o perfil alimentar e o valor nutritivo da dieta consumida por essas familias. $O$ método usado no estudo do consumo alimentar foi uma associação do recordatório com a pesagem direta de alimentos, cobrindo a alimentação de um dia.
A análise do valor nutritivo da dieta em calorias e nutrientes foi feita com base nas tabelas de composição de alimentos.7,11 O cálculo da adequação da dieta foi efetuado, tomando-se como referência as recomendaçб̃es do Comitê Misto FAO/OMS10.

\section{RESULTADOS}

A ingestão dos alimentos nas famílias consideradas está diretamente relacionada com a posse da terra. Entre os produtos animais, a came de boi e 0 ovo não são referidos apenas por $20 \%$ das familias sem terra, enquanto que o charque não atinge este percentual entre os grandes proprietários. Outros alimentos, como tomate, pimentão, macarrão e gorduras, também assinalam freqüencias inferiores a $20 \%$ entre as familias das duas primeiras categorias. A farinha de mancioca, o açúcar e o café são amplamente difundidos, sendo consumidos por mais de $90 \%$ das familias (Tabela 1).

Com relação ao consumo médio "per capita" (Tabela 2), observa-se que as quantidades consumidas aumentam à medida que aumenta a propriedade da terra, com exceção do charque, bolacha, macarrâo e farinha de mandioca. $O$ consumo de verduras não foi referido, por ser bastante reduzido nas quatro categorias, sendo indicada sua utilização apenas como tempero das preparaçōes.

O valor da dieta está expresso nas Tabelas 3, 4 e 5 , levando-se em conta a estratificação sócio-econórnica da amostra, permitindo, assim, inferências comparativas entre as quatro categorias.

Nas famílias sem terra o consumo médio de energia (1.605 calorias), de vitamina $A$ na forma de retinol e de niacina não alcançou o padrão reco. mendado, situando-se, respectivamente, nas adequações de $79,4 \%, 69,1 \%$ e $71,4 \%$ (Tabela 4). Estas evidências tornam-se ainda mais claras quando se observa que $10,8 \%, 81,6 \%$ e $27,9 \%$ dessas familias apresentaram, respectivamente, um consumo "per capita" de energia, retinol e niacina abaixo de $50 \%$ das recomendações diárias (Tabela 5).

Nas familias com propriedades rurais até 10 hec. tares, o baixo consumo energético ( 1.851 calorias) e de niacina $(11,3 \mathrm{mg})$ foram as principais restrições encontradas, correspondendo a $91,0 \%$ e $81,7 \%$, respectivamente, das recomendações (Tabelas 3 e 4 ). A prevalência de familias na faixa de mais baixa a adequação $(<50 \%)$ foi de $75,6 \%$ com deticiência de vitamina A e $20,2 \%$ de niacina (Tabela 5).

Nas farnilias com propriedades compreendidas entre 10 e 50 hectares, o consumo calórico e de nutrientes alcançou, em termos médios, mais de $100 \%$ do recomendado. Não obstante, levando-se em conta a freqüência por níveis de adequação (Ta- 
ROMANI, S. de A.M. \& AMIGO, H. Perfil alimentar e posse da terra na área rural do Estado de Pernambuco, Nordeste do Brasil. Rev. Saúde públ., S.Paulo, 20:369-76, 1986.

\section{TABELA 1}

Percentual de famílias rurais, de acordo com o consumo de diferentes alimentos, em quatro municípios do Agreste Pernambucano (Nordeste do Brasil), segundo a quantidade de terra possuída

\begin{tabular}{|c|c|c|c|c|c|}
\hline Alimentos $\left(^{*}\right)$ & $\begin{array}{c}\text { Terra } \\
\text { Possuída }\end{array}$ & Sem terra & $0-10$ ha & 10.50 ha & $50 \mathrm{e}+\mathrm{ha}\left({ }^{* *}\right)$ \\
\hline Carne de boi & & 0,0 & 21,3 & 34,2 & 41,0 \\
\hline Charque & & 27,1 & 30,2 & 38,2 & 0,0 \\
\hline Leite de vaca & & 55,8 & 58,9 & 73,0 & 94,9 \\
\hline Ovo & & 0,0 & 22,1 & 30,9 & 53,8 \\
\hline Cebola & & 32,1 & 34,5 & 52,0 & 94,9 \\
\hline Coentro & & 44,2 & 47,3 & 62,5 & 92,3 \\
\hline Cebolinha & & 21,7 & 23,3 & 38,8 & 61,5 \\
\hline Tomate & & 0,0 & 20,2 & 38,8 & 66,7 \\
\hline Pimentão & & 0,0 & 0,0 & 23,0 & 51,3 \\
\hline Arroz & & 25,8 & 31,0 & 54,6 & 94,9 \\
\hline Fubá/Xerém & & 38,8 & 54,3 & 53,9 & 46,2 \\
\hline Pão francês & & 43,3 & 39,1 & 49,3 & 74,4 \\
\hline Bolacha & & 24,2 & 23,6 & 34,9 & 41,0 \\
\hline Macarrão & & 0,0 & 0,0 & 31,6 & 48,7 \\
\hline Feijão mulatinho & & 57,1 & 59,7 & 63,2 & 71,8 \\
\hline Farinha de mandioca & & 95,4 & 95,3 & 97,4 & 92,3 \\
\hline Açúcar & & 99,2 & 100,0 & 100,0 & 100,0 \\
\hline Gorduras & & 0,0 & 0,0 & 36,8 & 64,1 \\
\hline Café & & 94,6 & 97,7 & 98,0 & 100,0 \\
\hline
\end{tabular}

${ }^{*}$ ) 0,0 indica alimentos consumidos por menos de $20 \%$ das famílias.

(**) Queijo, jerimum, chuchu, alface, cenoura, banana, laranja, biscoito, batata inglesa e doces foram referidos, apenas, pelas famílias com 50 e mais hectares de terra.

TABELA 2

Consumo médio diário "per capita" de alimentos, em gramas, de famílias rurais de quatro municípios do Agreste Pernambucano (Nordeste do Brasil), segundo a quantidade de terra possuída

\begin{tabular}{|c|c|c|c|c|c|}
\hline Alimentos & $\begin{array}{c}\text { Terra } \\
\text { Possuida }\end{array}$ & Sem Terra & $0-10$ ha & $10-50 \mathrm{ha}$ & $50 \mathrm{e}$ tha \\
\hline Carne de boi & & 40,47 & 54,10 & 53,48 & 101,74 \\
\hline Charque & & 31,73 & 34,38 & 40,32 & 34,81 \\
\hline Leite de vaca $\left(^{*}\right)$ & & 179,65 & 224,96 & 281,99 & 401,93 \\
\hline Ovo & & 29,82 & 30,39 & 44,32 & 43,08 \\
\hline Arroz & & 46,05 & 50,39 & 54,52 & 62,19 \\
\hline Fubá/Xcrém & & 112,70 & 113,48 & 115,47 & 144,03 \\
\hline Pão francês & & 77,27 & 71,36 & 95,14 & 113,97 \\
\hline Bolacha & & 48,32 & 56,06 & 59,62 & 48,75 \\
\hline Macarrão & & 43,06 & 33,55 & 40,53 & 37,37 \\
\hline Feij ão mulatinho & & 78,03 & 92,91 & 90,05 & 97,18 \\
\hline Farinha de mandioca & & 123,39 & 130,05 & 109,65 & 88,31 \\
\hline Açúcar & & 54,30 & 52,35 & 62,10 & 86,74 \\
\hline Gorduras $(*)$ & & 5,53 & 7,26 & 6,49 & 8,06 \\
\hline Café (infusão) $\left(^{*}\right)$ & & 122,05 & 111,75 & 129,23 & 147,52 \\
\hline
\end{tabular}

(*) $\mathrm{m} !$. 
ROMANI, S. de A.M. \& AMIGo, H. Perfil alimentar e posse da terra na área rural do Estado de Pernambuco, Nordeste do Brasil. Rev. Saúde públ., S.Paulo, 20:369-76, 1986.

\section{TABELA 3}

Consumo médio diário "per capita" de energia e nutrientes de famílias rurais de quatro municípios do Agreste Pernambuco (Nordeste do Brasil), segundo a quantidade de terra possuída

\begin{tabular}{|c|c|c|c|c|c|c|}
\hline \multirow{2}{*}{$\begin{array}{l}\text { Calorias e } \\
\text { Nutrientes }\end{array}$} & \multirow{2}{*}{$\begin{array}{c}\text { Terra } \\
\text { Possuída }\end{array}$} & \multicolumn{5}{|c|}{ Consumo Médio "Per Capita" } \\
\hline & & $\overline{\text { Sem Terra }}$ & 0.10 ha & $10.50 \mathrm{ha}$ & $50 \mathrm{e}$ tha & Amostra Total \\
\hline Calorias & & 1.605 & 1.851 & 2.192 & 3.017 & 1.932 \\
\hline Proteínas, $\mathrm{g}$ & & 50,6 & 63,0 & 75,6 & 113,6 & 65,5 \\
\hline Cálcio, mg & & 579 & 708 & 812 & 1.428 & 739 \\
\hline Ferro, mg & & 17,5 & 20,8 & 22,6 & 27,2 & 20,6 \\
\hline Retinol, mcg & & 357 & 673 & 990 & 1.123 & 681 \\
\hline Tiamina, mg & & 0,95 & 1,17 & 1,18 & 1,63 & 1,13 \\
\hline Riboflavina, mg & & 1,49 & 1,73 & 1,88 & 2,73 & 1,75 \\
\hline Niacina, mg & & 9,7 & 11,3 & 13,7 & 18,6 & 11,8 \\
\hline Vitamina $\mathrm{C}, \mathrm{mg}$ & & 42,5 & 48,5 & 65,9 & 89,0 & 53,5 \\
\hline
\end{tabular}

\section{TABELA 4}

Adequação média (\%) de energia e nutrientes de familias rurais de quatro municípios do Agreste Pernambucano (Nordeste do Brasil), segundo a quantidade de terra possuída

\begin{tabular}{lccccc}
\hline \multicolumn{1}{c}{$\begin{array}{c}\text { Calorias e } \\
\text { Nutrientes }\end{array}$} & $\begin{array}{c}\text { Terra } \\
\text { Possuída }\end{array}$ & \multicolumn{4}{c}{ Adequação Média (\%) } \\
\cline { 2 - 6 } & Sem Terra & $0-10$ ha & $10-50$ ha & 50 e + ha & Amostra Total \\
\hline Calorias & 79,4 & 91,0 & 107,6 & 137,4 & 93,2 \\
Proteinas, g & 142,1 & 173,7 & 213,0 & 284,7 & 177,6 \\
Cálcio, mg & 121,5 & 144,5 & 178,9 & 289,7 & 152,3 \\
Ferro, mg & 194,0 & 225,5 & 258,0 & 313,3 & 226,6 \\
Retinol, mcg & 69,1 & 103,8 & 143,4 & 266,6 & 109,7 \\
Tiamina, mg & 116,1 & 139,0 & 144,5 & 177,4 & 134,4 \\
Riboflavina, mg & 131,7 & 149,9 & 163,9 & 218,2 & 150,5 \\
Niacina, mg & 71,4 & 81,7 & 102,6 & 125,5 & 85,2 \\
Vitamina C, mg & 172,5 & 196,6 & 275,5 & 349,6 & 214,4 \\
\hline
\end{tabular}

\section{TABELA 5}

Distribuição percentual das famílias rurais de quatro municípios do Agreste Pernambucano (Nordeste do Brasil), segundo a quantidade de terra possuída.

\begin{tabular}{|c|c|c|c|c|c|c|c|c|c|c|c|c|c|}
\hline \multirow{3}{*}{$\begin{array}{l}\begin{array}{c}\text { Calorias } \\
\mathrm{e} \\
\text { Nutrientes }\end{array} \\
\text { Calorias }\end{array}$} & \multirow{3}{*}{$\begin{array}{c}\text { Terra } \\
\text { Possuída } \\
\text { Níveis de } \\
\text { Consumo }\end{array}$} & \multicolumn{3}{|c|}{ Sem Terra } & \multicolumn{3}{|c|}{$0-10 \mathrm{ha}$} & \multicolumn{3}{|c|}{$10 \cdot 50 \mathrm{ha}$} & \multicolumn{3}{|c|}{$50 \mathrm{e}+\mathrm{ha}$} \\
\hline & & \multicolumn{3}{|c|}{$<50 \%<75 \%<90 \%$} & \multicolumn{3}{|c|}{$<50 \%<75 \%<90 \%$} & \multicolumn{3}{|c|}{$<50 \%<75 \%<90 \%$} & \multicolumn{3}{|c|}{$<50 \%<75 \%<90 \%$} \\
\hline & & 10,8 & 46,6 & 71,2 & 5,0 & 35,2 & 55,8 & 2,6 & 15,8 & 34,9 & 0,0 & 5,1 & 12,8 \\
\hline Proteínas, $\mathbf{g}$ & & 3,8 & 11,7 & 22,5 & 0,4 & 5,1 & 9,8 & 0,7 & 3,3 & 3,3 & 0,0 & 0,0 & 0,0 \\
\hline Cálcio, mg & & 8,0 & 29,7 & 40,5 & 5,0 & 17,4 & 24,8 & 2,0 & 10,6 & 17,2 & 0,0 & 0,0 & 7,7 \\
\hline Ferro, mg & & 1,2 & 2,9 & 6,2 & 0,4 & 0,8 & 2,4 & 0,7 & 0,7 & 1,4 & 0,0 & 0,0 & 0,0 \\
\hline Retinol, $\mathrm{mcg}$ & & 81,6 & 84,9 & 86,2 & 75,6 & 80,3 & 82,6 & 61,8 & 70,3 & 72,9 & 30,8 & 38,5 & 46,2 \\
\hline Tiamina, mg & & 5,8 & 24,1 & 39,9 & 2,3 & 9,3 & 22,9 & 1,4 & 9,3 & 19,8 & 0,0 & 0,0 & 5,1 \\
\hline Riboflavina, mg & & 5,0 & 13,8 & 24,2 & 2,0 & 8,6 & 16,0 & 2,0 & 6,6 & 7,9 & 0,0 & 0,0 & 2,6 \\
\hline Niacina, mg & & 27,9 & 64,6 & 77,9 & 20,2 & 53,1 & 67,4 & 9,3 & 38,2 & 53,3 & 5,1 & 20,5 & 28,2 \\
\hline Vitamina $\mathrm{C}, \mathrm{mg}$ & & 8,4 & 18,0 & 30,5 & 6,6 & 23,7 & 30,7 & 2,0 & 9,2 & 13,8 & 0,0 & 0,0 & 0,0 \\
\hline
\end{tabular}


bela 5), ressalta-se que $2 / 3$ e $1 / 3$, respectivamente, das familias das duas categorias, consumiram menos de $50 \%$ da quota recomendada de vitamina $\mathrm{A}$.

O valor da dieta, expresso em valores absolutos ou em médias de adequação, particularizado segundo os diferentes nutrientes (Tabelas 3 e 4), nas quatro categorias de posse da terra, está diretamente relacionado à condição sócio-econômica, aqui caracterizada pela quantidade de terra possuida. Enquanto as familias sem terra consumiram, em média, 1.605 calorias, correspondendo a uma adequação de $79,4 \%$, as possuidoras de mais de 50 hectares apresentaram um consumo médio de 3.017 calorias, equivalente a $137,4 \%$ da adequação. A ingestão de todos os nutrientes foi duas a três vezes superior entre as familias que compõem o quarto grupo amostral (50 e + ha). Em conseqüência, as médias de adequação apresentaram, também, comportamento idêntico, ou seja, aumentaram, proporcionalmente, em relação ao tamanho da propriedade.

A distribuição de niveis de consumo por faixas de adequação (Tabela 5) indicou que a vitamina $A$ (expressa em termos de retinol) foi o nutriente mais restritivo, com $81,6 \%, 75,6 \%$ e $61,8 \%$ das familias sem terra, proprietárias de até 10 hectares e de 10 a 50 hectares, respectivamente, não atingindo o limite de $50 \%$ das recomendaçōes.

A contribuição, em termos percentuais, dos diversos grupos de alimentos para a formação da dieta consta da Tabela 6, através da qual se observa que o consumo de produtos animais apresenta uma tendência crescente em relação à posse da terra,

TABELA 6

Percentual de calorias fornecidas pelos grupos básicos de alimentos de famílias rurais de quatro municípios do Agreste Pernambucano (Nordeste do Brasil), segundo quantidade de terra possuída.

\begin{tabular}{lcrrrr}
\hline Grupos de Alimentos & $\begin{array}{c}\text { Terra } \\
\text { Possuída }\end{array}$ & Sem Terra & $0-10$ ha & $10-50$ ha & 50 e + ha \\
\cline { 3 - 6 } Produtos Animais & 10,5 & 13,3 & 15,9 & 23,4 \\
Verduras e Frutas & 1,4 & 1,5 & 2,5 & 4,7 & 56,1 \\
Grãos e Raízes & 73,8 & 72,6 & 67,2 & 15,8 \\
Açúcares e Gorduras & 14,3 & 12,6 & 14,5 & \\
\hline
\end{tabular}

$10,5 \%$ na categoria dos sem terra e $23,4 \%$ na dos proprietários de 50 e mais hectares. $O$ inverso ocorreu com a participação dos alimentos que compõem o grupo dos "grãos e raízes", decrescendo de $73,8 \%$ para $56,1 \%$ na dieta das famílias possuidoras de mais de 50 hectares.

Com relação à contribuição das proteínas, gorduras e carboidratos (Tabela 7), evidencia-se, também, uma relação direta com a quantidade de área possuída, para os dois primeiros nutrientes. Em contraposição, os valores dos carboidratos diminuem à medida que melhoram as condições sócio-econômicas. Vale ressaltar que, apenas na categoria de 50 e mais hectares, a dieta tende ao equilíbrio, com $15,1 \%, 18,5 \%$ e $67,7 \%$ de contribuição protídica, lipídica e glicídica, respectivamente.

TABELA 7

Contribuição percentual dos protídeos, lipídeos e glicídeos para o valor calórico da dieta de famílias rurais de quatro municípios do Agreste Pernambucano (Nordeste do Brasil), segundo a quantidade de terra possuída

\begin{tabular}{lcccccc}
\hline \multicolumn{1}{c}{ Especificação } & $\begin{array}{c}\text { Terra } \\
\text { Possuída }\end{array}$ & Sem Terra & $0-10$ ha & $10-50$ ha & 50 e +ha & $\begin{array}{c}\text { Amostra } \\
\text { Total }\end{array}$ \\
\hline Protídeos & & 12,6 & 13,6 & 13,8 & 15,1 & 13,5 \\
Lipídeos & 8,9 & 10,3 & 13,5 & 18,5 & 11,6 \\
Glicídeos & 80,8 & 78,4 & 74,7 & 67,7 & 76,9 \\
\hline
\end{tabular}

\section{COMENTÁRIOS}

O consumo alimentar se constitui um dos melhores indicadores da situação de alimentação e nutrição das populações, e, por sua vez, a situação da alimentação reflete com muita precisão o nível de vida dessas populações.
A importância do estudo do consumo está mais voltada à quantificação do problema e à identificação de seus desvios, principalmente em áreas onde os problemas carenciais parecem se agravar a cada dia com as estiagens, as migrações, o poder aquisitivo, a má distribuiçâo das terras, além de outras. 
O estado nutricional deficiente, influenciado pelo estado alimentar (subalimentação, deficiências quali e quantitativas) representa uma consequêencia do quadro de pauperismo de uma população, como já demonstrado por outros autores 1,14 .

No presente trabalho, ao analisar a situação nutricional através do consumo alimentar segundo a posse da terra, confirmou-se uma relação direta entre quantidade e qualidade do consumido com a extensão da terra possuída, o que reflete a importância desta variável como determinante do estado nutricional das populações.

A frequiência de consumo dos alimentos que constitui a cesta alimentar, representa o ponto de partida da caracterização alimentar. $O$ perfil quali e quantitativo da dieta das familias, praticamente, reproduz os achados do Estudo Nacional de Despesas Familiares (ENDEF) para a Região Nordeste, em 1974.9

Os dados sobre adequação indicam déficit caló. rico, de retinol e de tiamina. 0 déficit calórico confirma o encontrado em outras pesquisas $6,13,17$, que afirmam ser o déficit energético sério problema que vem afetando as populações nordestinas. Assim, em 1974, o IBGE9 encontrou para o Nordeste rural uma adequação média de $93,2 \%$ equivalente a uma ingestão média de 1.982 calorias por comensal dia e, na presente pesquisa, 0 aporte calórico para a amostra total estudada foi de 1.932 per capita, com uma adequação média atingindo, exatamente, $93,2 \%$ do recomendado.

O nutriente, cuja deficiência mais ressalta entre as familias. é a vitamina $A$ (expressa em termos de retinol), confirmando o encontrado pelo IBGE9 e por outros autores 6,13 . Vale salientar, ainda, que na população de pré-escolares, que compõe a amostra do presente estudo, foram detectados baixos níveis de retinol sérico.

As necessidades protéicas são amplamente alcançadas em todos os grupos amostrais, sendo insignificantes os percentuais de familias com adequação protéica abaixo do limite de $90 \%$ das recomendações nutricionais, com exceção para o primeiro grupo das familias sem terra, com $22,5 \%$ sem atingir o nível de consumo protéico ideal.

A distribuição percentual de protídeos, lipídeos e glicídeos, para o valor calórico da dieta indicam que as dietas destas populações têm uma baixa densidade energética e, assim, o aporte calórico das gorduras alcançam $11,6 \%$, cifra bastante reduzida quando comparada com os $45 \%$ utilizados em alguns países desenvolvidos 12 e distante, também, das sugestões de alguns peritos internacionais que apontam como nível razoável de aporte de gordura no consumo calórico total, de $30 \%$ a $35 \% 15$. A situação é ainda mais delicada, quando se observa que nos componeses sem terra, apenas $8,9 \%$ do total das calorias consumidas provêm dos lipídeos. $\mathrm{O}$ aporte protéico pode ser considerado satisfatório ao alcançar $13,5 \%$ para a amostra total e é relativamente homogêneo nas quatro classes sócio-econômicas que compõem a amostra. Esta cifra é similar a encontrada em outras áreas, onde a média é de $11 \% 16$.

Sem dúvida, esta baixa densidade energética das dietas deve ser estudada com maior profundidade, seja do ponto de vista das repercussōes nutricionais na população, e/ou dos possíveis subsídios para programas de nutrição. Sobre as repercussões nutricionais, este tipo de dieta pode estar comprotendo seriamente a assimilação de alguns nutrientes, especificamente, das vitaminas lipossolúveis, ou poderia estar afetando as reais necessidades energéticas das populações rurais, submetidas, em sua maioria, a um trabalho físico intenso. Do ponto de vista dos programas de nutrição (suplementação alimentar, subsídios de alimentos, políticas creditícias e outros) constitui-se aspecto importante a ser considerado, vez que 0 problema alimentar não é apenas quantitativo, onde se deve somente suprir o déficit calórico, senão, também, contribuir para uma adequada estruturação da dieta.

Finalmente, duas importantes conclusões podem ser obtidas deste trabalho. A primeira, é a importância fundamental da distribuição agrária como determinante do estado nutricional das populaçōes. Para obter importantes modificações naquele estado nutricional é necessário realizar políticas e programas destinados à melhor distribuição das terras disponíveis, acompanhadas das atividades específicas de apoio. A segunda, é o sério problema alimentar em que vive grandes setores da população destas áreas rurais onde algumas familias, dificilmente, ingerem $50 \%$ das necessidades calóricas. 
ROMANI, S. de A.M. \& AMIGO, H. Perfil alimentar e posse da terra na área rural do Estado de Pernambuco, Nordeste do Brasil. Rev. Saúde públ., S.Paulo, 20:369-76, 1986.

ROMANl, S. de A.M. \& AMIGO, H. ᄃ Alimentary profile and land ownership in rural Pernambuco, Northeastern Brazil ] . Rev.Saúde públ., S.Paulo, 20:369-76, 1986.

ABSTRACT: A total of 689 families from rural areas of Northeast Brazil were studied; they were divided into four categories, according to land tenure: no land owner ( $-L O)$, small land owner (s - LO) who had up 10 hectare of land, intermediate land owner (i-LO) 10 to 50 hectares and big land owner (b-LO) who had more than 50 ha of land. The mean energy intake of the $n-L O$ was 1,605 calories, which represented $79,4 \%$ of the requirement of this group. For the other groups (s - LO, i - LO and $b-L O)$ this average increased in relation to the area of land owned. The energy intake of the $b$ - LO groups is quite high (about 3,000 cal) corresponding to the average values of the developed countries. Or the average, protein deficiency was not detected among the groups. The total calory value (TCV) of the diet was as follows: $13 \%$ protein, $11 \%$ lipids an $76 \%$ carbohidrates. Protein and lipid intakes increase with the area of the land owned, but carbohidrates decrease. Roots and grains were the main contributors to the TCV but their contribuition decreased as the area of the land owned increased. On the other hand, the importance of the animal products increased in proportion to land size. No differences were detected among the categories concerning two other groups of food stuffs: vegetables and fruit, sugar and oil.

UNITERMS: Nutrition surveys. Food consumption. Ownership. Nutrition status.

\section{REFERENCIAS BIBLIOGRAFICAS}

1. ALVES, E.L. Desnutrição e pobreza no Brasij : algumas evidências. Cad.Peq., (29): 77-86, 1979.

2. BARROS, J.A.; CARVALHO, E.; MORAIS, H.; PERRUCI, G. \& PINO, P. As transformaçōes sociais e econômicas no nordeste: desnutrição e saúde. Recife, Universidade Federal de Pernambuco. Departamento de Medicina Social, 1984. [ Mimeografado]

3. BATISTA FILHO, M. \& TORRES, M.A.A. Acesso à terra e situação nutricional em populaçōes do semi-árido nordestino. Rev.pernamb.Des., 9(1): 101-18, 1982.

4. BORGES, V.M. da R. Um estudo sobre consumo e adequação alimentar em populações de baixa renda: Grande Recife. Recife, 1975. [Dissertação de Mestrado - Centro de Ciências Sociais e Aplicadas UFPE J.

5. CASTRO, J. O valor de alimentação: um estudo econômico das condições de vida das classes operárias no Recife. Bol.Dep.Ind.Trab.Com., Recife, (5):177, jan. 1935.

6. DEUS, M.B. de; COELHO, H. de A.L. \& ROMANI, S. de A.M. Consumo alimentar em Pernambuco; um estudo em 6 microrregiōes. In: Perez, E.P.; Lira, P.I.C. de \& Romani, S. de A.M. Alimentaçāo e nutriçāo no Nordeste (uma coletônea). Recife, CJC/CEAS/ CENTRU/ETAPAS/FASE/SACTES, 1983. p.157.64.

7. FLORES, M.; MENCHÜ. M.T.: LARA, M.Y. \& ARROYAVE, G. Contenido de Vitamina $A$ en el alimentos incluídos en la tabla de composición de alimentos para uso en América Latina. Arch.lationo. amer.Nutr., 19: 311-41, 1969.

8. FUNDAÇÃO GETÛLIO VARGAS/INSTITUTTO BRASILEIRO DE ECONOMIA. Food consumption in Brazil: family budget survey in the early, 1960 's. Jerusalem, Keter Press. 1970.

9. FUNDAÇĀO IBGE. Consumo alimentar e antropometria. Rio de Janeiro, 1977. (Estudo Nacional de Despesa Familiar, v. 1, t. 1).
10. JOINT FAO/WHO "AD HOC" EXPERT COMMITTEE ON ENERGY AND PROTEIN REQUIREMENTS, Rome, 1971. Report. Geneva, World Health Organization, 1973. (WHO-Techn.Rep.Ser., 522).

11. LEUNG, W.T. W. \& FLORES, M. Tabla de composición de alimentos para uso en América Latina. Guatemala, Instituto de Nutrición de Centro América y Panamá, 1970.

12. LIRA, P.I.C. de; AMIGO, H.; ROMANI, S. de A.M. \& TORRES, M. A.A. Estado nutricional de crianças menores de 6 anos segundo posse da terra, em áreas rurais do Estado de Pernambuco, Nordeste do Brasil. Arch.Latinoamer.Nutr., 35 : 247-57, 1985.

13. LUCENA, M.A.F. de; BAZANTE, M.O.; TORRES, M.A.A. \& BATISTA FILHO, M. Padrōes alimentares de famílias rurais do trópico semi-árido (Nordeste do Brasil). Aliment.e Nutr., S.Paulo, 5(6): 51-8, 1964.

14. MONTEIRO, C.A. A epidemiologia da desnutrição protéico-calórica em núcleos rurais do Vale do $\mathrm{Ri}$ beira. Sāo Paulo, 1977. [ Dissertação de Mestrado - Faculdade de Medicina da USP J.

15. ORGANIZACION DE LAS NACIONES UNIDAS PARA LA AGRICULTURA Y LA ALIMENTACION. Las grasas y aceites en la nutrición humana; informe de una consulta de expertos. Roma, 1980. (Coleción FAO: Alimentación y Nutrición, 20).

16. PERISSE, J.: SIZARET, F. \& FRANÇOIS, P. Nutr. Newsletter (FAO), 7 (3): 1, 1969. Apud JOINT FAO/WHO "AD HOC" EXPERT COMMITTEE ON ENERGY AND PROTEIN REQUIREMENTS, Rome, 1971. Report, Geneva, World Health Organization, 1973. (WHO-Techn.Rep.Ser., 522).

17. ROMANI, S. de A.M. Inquérito de consumo alimentar no município de Ferreiros - Zona da Mata Seca de Pernambuco. Recife, 1974. [Dissertaçāo de Mestrado - Centro de Ciências da Saúde da UFPE $\sqsupset$. 
ROMANI, S. de A.M. \& AMIGO, H. Perfil alimentar e posse da terra na área rural do Estado de Pernambuco, Nordeste do Brasil. Rev. Saúde públ., S. Paulo, 20:369-76, 1986.

18. ROSEMBERG, E.; SAMPAIO, Y.; SANATA, G. \& BARBOSA, T. Politicas agricolas orientadas para a nutriçāo. Brasília, Instituto Nacional de Alimentação e Nutrição, 1977.

19. TORRES, M.A.A. Estado nutricional e aspectos sócio-econômicos de famílias rurais do trópico semi-árido (Nordeste do Brasil). Recife, 1982. [ Dissertação de Mestrado - Centro de Ciências da Saúde da UFPE ].
20. US INTERDEPARTMENTAL COMMITTEE FOR NATIONAL DEVELOPMENT. Northeast Brazil: nutrition survey: March-May 1963. Washington, D.C., 1965.

Recebido para publicaç̃ó em 02/04/1986

Reapresentado em 22/07/1986

Aprovado para publicaçāo em 01/07/1986 